Blind Landscape, water vestiges in Santiago, Chile

\title{
Paisaje Ciego, vestigios del agua en la ciudad de Santiago de Chile
}

\author{
CAMILA KUNCAR RÍOS*·Madrid, España·camikuncar@gmail.com \\ Fecha de recepción: 28 de agosto 2017 - Fecha de aceptación: 16 de octubre 2017
}

\section{INTRODUCCIÓN}

Paisaje ciego es el nombre de una exposición de arte que ha sido el resultado de una residencia artística colaborativa desarrollada en Cancha, Santiago*, en la que se realizó una relectura de antiguas cartografías en torno a los cursos de agua del Casco Histórico de la ciudad de Santiago de Chile, utilizando como método una serie de recorridos a pie para ir en la búsqueda y encuentro de vestigios asociados a la captación, distribución y almacenamiento de una extensa red de acuíferos que en alguna época pasada funcionó alimentando los edificios de la ciudad, y que hoy yacen en el abandono, ocultos e invisibilizados bajo el cemento y la construcción moderna. Como resultado, esta investigación reveló la existencia de ruinas en un estado conmovedor. algunas de ellas aún preservan caudalosas aguas subterráneas. Estos vestigios contienen el potencial de documentar el patrimonio nacional del agua y con esto se pretende darle visibilidad y volver a reconstruirlo, generando una reflexión crítica en torno a la historia, las transformaciones y el devenir de las aguas en la región.

\section{ABSTRACT}

Blind Landscape is the name of an art exhibition, that was the result of an artistic collaborative residence, developed in Cancha Santiago, in which a reinterpretation of ancient cartographies of the water courses located in the historic part of the city was made; using as method, a series of walking tours in the search and encounter of the vestiges associated with the capture, distribution and storage of an extensive network of aquifers, which, in the past, provided the buildings of the city with wate past, provided the buildings of and which today lies in abandonment, concealed and hidden under cement and modern constructions. As a result, this research revealed the existence of aquifer ruins in impressive conditions, some of which still preserve plentiful groundwater. These ruins contain the potential to document the national heritage of water, and it is intended to give visibility and to rebuild it, generating a critical reflection on the history, transformations and the evolution of the water in the region.
El interés por indagar la existencia de vestigios del agua en el casco histórico de Santiago, surge de una experiencia previa de caminar por las aguas del territorio metropolitano a través de una ruta propuesta por el colectivo de Exploraciones Urbanas - Territorios a Pie ${ }^{[1]}$ a la Universidad de Chile. La ruta, que comprendió sesenta kilómetros y quince clases caminadas, evidenció las complejidades del recurso y dio cuenta de una serie de conflictos y realidades socioterritoriales en torno al tema de las aguas en la región (FIGURAS 1 y 2).

Desde esta visión territorial, se decide indagar en el origen de la ciudad, en su casco histórico, con el objetivo de encontrar vestigios que sirvan para comenzar a reconstruir la historia y transformaciones sucesivas de los cursos de agua, que originalmente irrigaban el valle de Santiago. Dándole un valor a la exploración directa del territorio a través de recorridos a pie, escuchas activas, recolección de relatos, de imágenes y de todas las pistas necesarias para armar un primer mapeo. Considerando significativamente la importancia de la memoria, de volver a recordar la ciudad olvidada, soterrada, desde donde surgen los siguientes cuestionamientos; ¿̇Fueron los cursos de agua condicionantes en la forma urbana de Santiago? ¿̇Cómo es el sistema de aguas actual en su relación capital-territorio impuesto por el modelo económico neoliberal que nos rige? ¿̇ ¿̇e podría rescatar la memoria del agua, haciéndola visible a través de una intervención tangible en el paisaje?

* Arquitecta de la Facultad de Arquitectura y Urbanismo de la Universidad de Chile. Participó en el año 2010 del Laboratorio de Arte Urbano Stalker, Observatorio Nómada. Académica durante el año 2012 del Curso de Formación General "Territorios Cruzados" basado en el proyecto homónimo que contó con el patrocinio de la Universidad Tecnológica Metropolitana (UTEM), Universidad de Artes, Ciencias y Comunicación (UNIACC) y Universidad de Chile, desarrollando el tópico de las exploraciones urbanas.

** Cancha es una iniciativa privada con fines públicos que promueve la investigación y producción multidisciplinar de casco histórico de Santiago de Chile. Se ubica en el edificio patrimonial de Merced 738, en la casa que perteneció a la familia Montt donde vivieron los ex presidentes Manuel y Pedro Montt entre los años 1839 y 1894 . Véase http:// canchasantiago.wixsite.com/cancha

[1] Exploraciones Urbanas - Territorios a Pie, es un colectivo interdisciplinario que se basa en la práctica del caminar para la realización de investigaciones del territorio urbano. Las rutas que se realizan comprenden territorios extensos, que permiten comprender la ciudad como un ente complejo, traspasando los límites físicos y políticos que la dividen y superando los propios límites mentales. El sinfín de estímulos del recorrido y el acto repetitivo del caminar, invitan a un estado de introspección, mientras que el cuerpo en sí mismo y el andar del grupo modifica el paisaje e interviene los lugares atravesados. La ciudad se convierte en el espacio de aprendizaje. Las derivas y sus cartografías permiten la construcción de una herramienta colaborativa para el levantamiento de problemáticas y posteriormente de propuestas para el accionar ciudadano. Hoy en día, el proyecto funciona principalmente en el ámbito académico, como curso de carácter optativo interdisciplinario que se lleva acabo en distintas universidades de Santiago de Chile. 
1. Mapa realizado de manera colaborativa con los estudiantes y participantes de la ruta por las aguas de Santiago realizada por el colectivo de Exploraciones Urbanas Territorios a Pie en la Universidad de Chile. Fotografía de María José Araya, noviembre 2014.
2. Ruta por el Río Mapocho con Exploraciones Urbanas - Territorios a Pie. Fotografía de la autora, octubre 2014
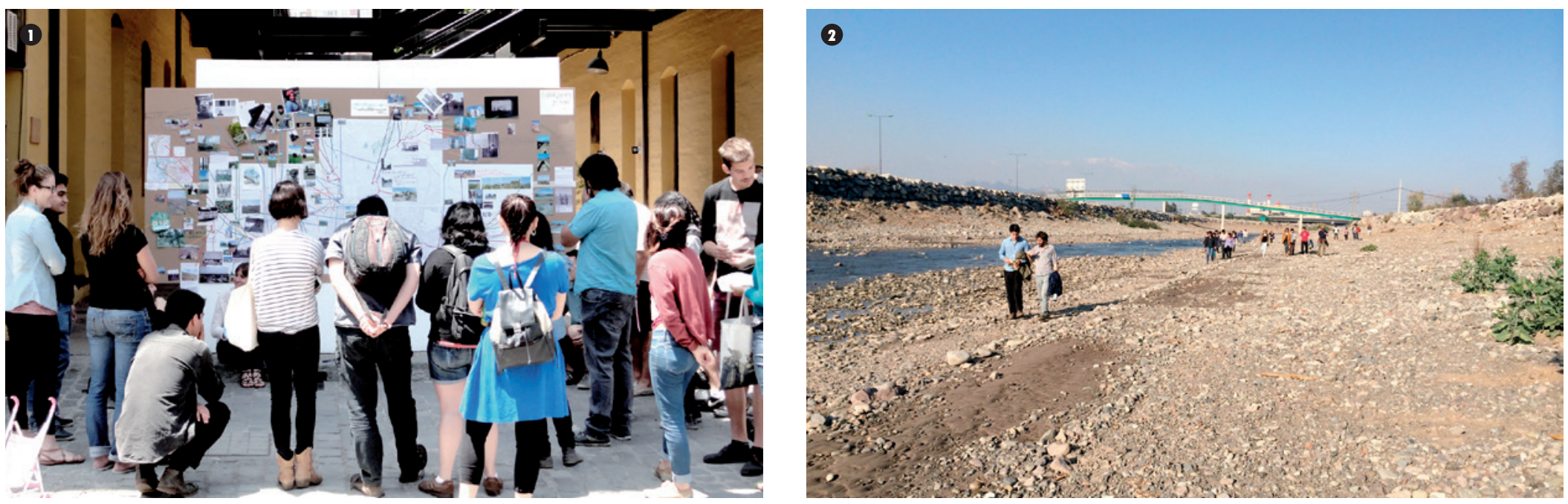

Las cartografías revisadas ponen en evidencia que la primera ciudad de Santiago estuvo delimitada por las aguas que en ese entonces circulaban por la ciudad, y que, posteriormente, hubo una historia de al menos un siglo relacionada con el agua, hasta su desaparición casi absoluta. Los vestigios encontrados tienen el potencial de articular esta historia y descubrir el valor del patrimonio hídrico de Santiago. El arte será el vehículo a través del cual se develarán los descubrimientos de esta investigación, en una serie de instancias que se explican en detalle más adelante.

La residencia se ha desarrollado de manera colaborativa con la artista audiovisual Claudia Aravena Abugosh, quien ha investigado y documentado "La ciudad de los ciegos", compuesta por los desplazamientos cotidianos de cientos de no videntes quienes trabajan comercializando productos con pequeños carros móviles que ellos mismos trasladan desde el edificio de Cancha Santiago, hacia distintos puntos del casco histórico. Claudia realizó grabaciones audiovisuales a las acciones cotidianas realizadas por ellos, que resultan casi invisibles para la ciudad.

La exposición ha sido nombrada Paisaje Ciego, un juego de palabras que hacen alusión a las realidades ocultas que conviven entremezcladas en el casco histórico de la ciudad, las que serán reveladas de manera cruzada a través de la muestra.

\section{RELECTURA DE CARTOGRAFÍAS E INVESTIGACIONES}

La ciudad de Santiago de Chile fue fundada delimitándose entre tres cursos de agua y un hito histórico: por el oriente, la ladera poniente del Huelén ${ }^{[2]}$; por el norte, el pedregoso lecho del río Mapocho y por el poniente, la Cañada de García Cáceres, que es actualmente la avenida Brasil (Piwonka, 1999, p. 34). Lo anterior se puede observar en la representación cartográfica que el investigador e historiador chileno Tomás Thayer Ojeda realiza sobre la ciudad de Santiago en el año 1600.

Por su parte, el sacerdote jesuita Alonso Ovalle escribía sobre Santiago en el siglo XVI:
De este río se sangra por la parte del oriente un brazo o arroyo, el cual, dividido en otras tantas cuantas son las cuadras que se cuentan de norte a sur, entran por todas ellas, de manera que a cada cuadra corresponde una acequia, la cual, entrando por cada una de las orientales, va entrando por todas las que le siguen a la hila y consiguientemente por todas las calles transversales, teniendo en estas sus puentes para que puedan entrar y salir las carretas que traen la provisión a la ciudad; con que no viene a haber en toda ella cuadra ni casa por donde no pase un brazo de agua muy copioso, que barre y lleva toda la basura e inmundicias del lugar, dejándolo muy limpio (...) Todas estas acequias desaguan al poniente y salen a regar mucha cantidad de huertos y viñas que están plantadas por aquella parte ${ }^{[3]}$ (Piwonka, 1999, p. 34).

[2] El cerro Huelén, nominado así durante el período incaico y actualmente conocido como cerro Santa Lucía, es de gran importancia ya que allí se encontró el primitivo núcleo de distribución de agua de riego y, especialmente, de agua potable colonial (Piwonka, 1999, p. 33).

[3] Alonso de Ovalle, Histórica relación del reyno de Chile i de las misiones que ejercita la Compañía de Jesús, 1969, p. 173 (Piwonka, 1999, p. 34) 
3. Croquis de la ciudad de Santiago durante el siglo XVI por Tomás Thayer Ojeda. Intervenido señalando en color celeste las aguas que delimitaban la ciudad. Colección Biblioteca Nacional de Chile.

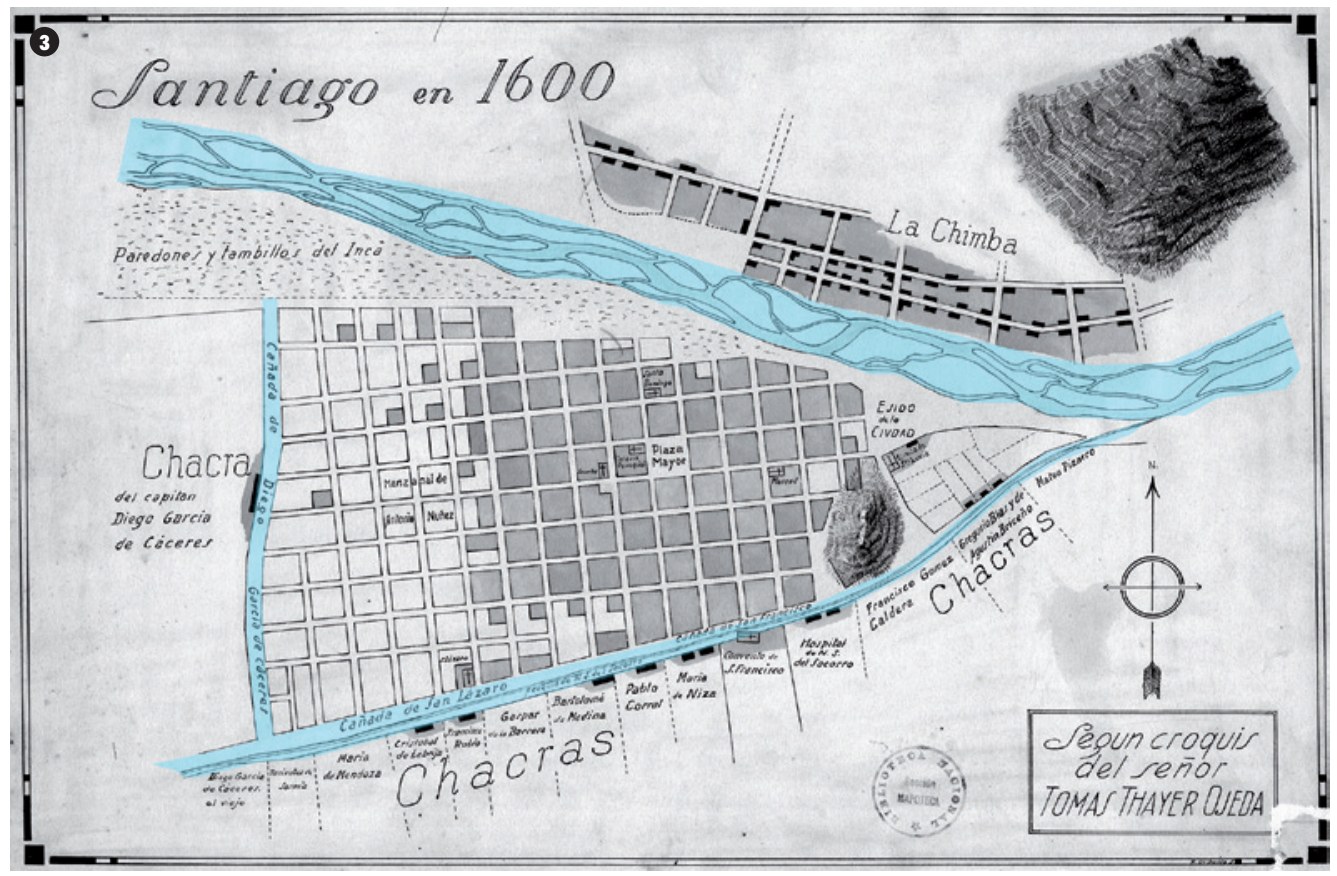

En la entusiasta descripción de Alonso de Ovalle sobre la ciudad de Santiago del siglo $X V I$, se evidencia la presencia de abundantes aguas que corrían a través de acequias a tajo abierto distribuidas por toda el área central de la ciudad.

En los últimos años los arquitectos e investigadores José Rosas Vera, Germán Hidalgo Hermosilla y Wren Strabucchi Chambers ${ }^{[4]}$ (2013) han realizado investigaciones y restituciones de las cartografías del casco histórico producidas y clasificadas originalmente por el ingeniero Alejandro Bertrand ${ }^{[5]}$. En la reelaboración que los arquitectos realizan del plano de la red de acequias de Santiago de 1890 del ingeniero Bertrand, se logra comprender de mejor manera cómo se distribuía el entramado de las aguas que servían a la ciudad en aquellos años.

En el artículo ${ }^{[6]}$ de los arquitectos se indica que:

Aunque no se detallan explícitamente en la leyenda de los rollos, se distinguen al menos tres tipos de cursos de agua: canalizadas bajo calzada, canalizadas abiertas y zanja irregular. El primer tipo es la más común y se asocia al trazado de acequias que atraviesan las manzanas y calles; y el tercero, corresponde a canales que corren a lo largo de las calles, que funcionan como
4. Proyecto de Alcantarillado y ensanche del servicio de agua potable: informe presentado al Supremo Gobierno de Chile. Santiago, 1904. En línea punteada blanca se observa la red de aguas que se distribuía subterránea y superficialmente. Colección Biblioteca Nacional de Chile.

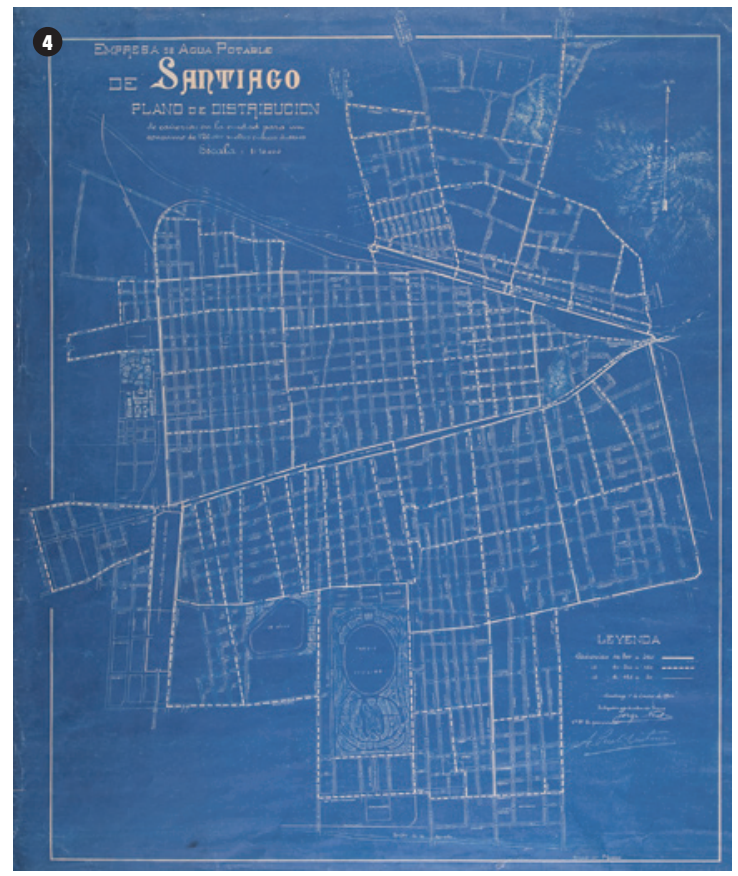

receptores de aguas servidas tales como el canal de Negrete (actual avenida Brasil), o como surtidores de agua tales como el canal San Miguel (en la actualidad avenida 10 de julio). Se puede observar que la red de acequias no solo abarca toda el área urbana, sino también que existe una clara coincidencia entre la estructura de aguas y esta (Rosas, Hidalgo \& Strabucchi, 2013).

La investigación de los arquitectos supone una importante contribución de creación intelectual y una ópera técnica sin precedentes a los estudios gráficos y planimétricos de la ciudad de Santiago. Y siendo esa la principal misión de su investigación, no se centran específicamente

[4] José Rosas Vera, Germán Hidalgo Hermosilla y Wren Strabucchi Chambers, arquitectos y académicos de la Pontificia Universidad Católica de Chile, de la Facultad de Diseño, Arquitectura y Estudios Urbanos, han dedicado gran parte de sus estudios al casco histórico de Santiago, a través de la reinterpretación y la restitución de las cartografías históricas del área central de la ciudad.

[5] Alejandro Bertrand fue un ingeniero civil, geógrafo e ingeniero en minas de la Universidad de Chile, quien estuvo a cargo de un nuevo plano de Santiago, usando para ello el registro de todas las calles de la ciudad, con el fin de sacar los alcantarillados y acequias del interior de las manzanas y mejorar, a nivel de superficie, las vías para el tránsito vehicular y tranviario (Rosas, Hidalgo \& Strabucchi, 2013).

[6] Cita extraída del artículo El callejero de Bertrand, Lecciones del plano detallado de Santiago de 1890, en Revista 180 número 32 (2013). Investigación FONDECYT n 11 10684: "Santiago 1890. La calle como soporte y tránsito hacia la modernidad. Transcripción y montaje planimétrico del catastro de calles de Alejandro Bertand. 2011 -2014" Investigadores: Rosas, Hidalgo y Strabucchi. 
5. Mapa mental de los vestigios del agua en el casco histórico. Apuntes de campo de la autora, noviembre 2014.
6. Pozo profundo en funcionamiento de la Galería Alessandri. Fotografía de la autora, trabajo de campo, diciembre 2014
5

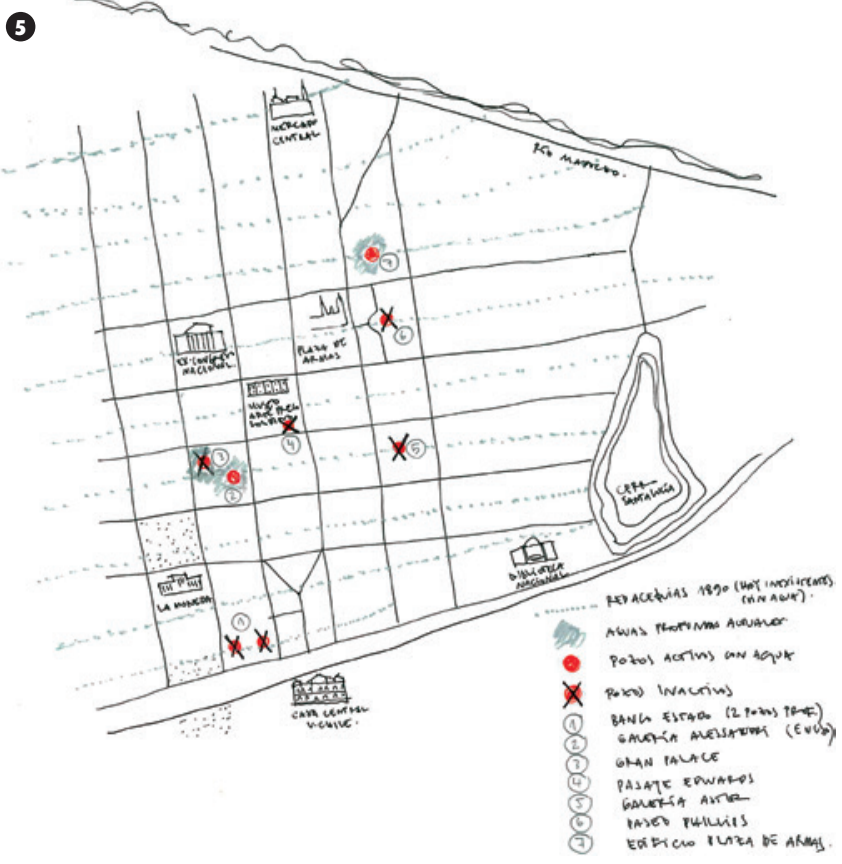

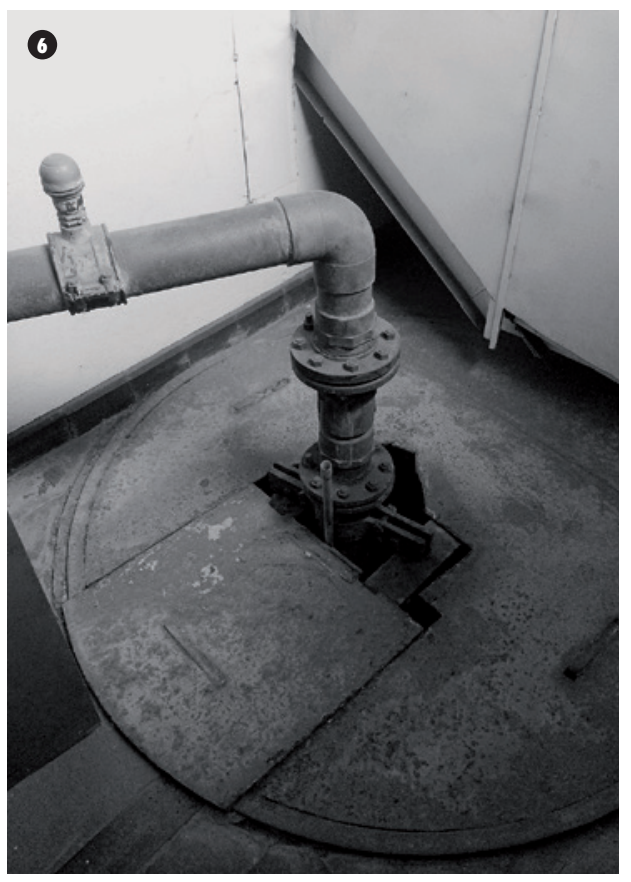

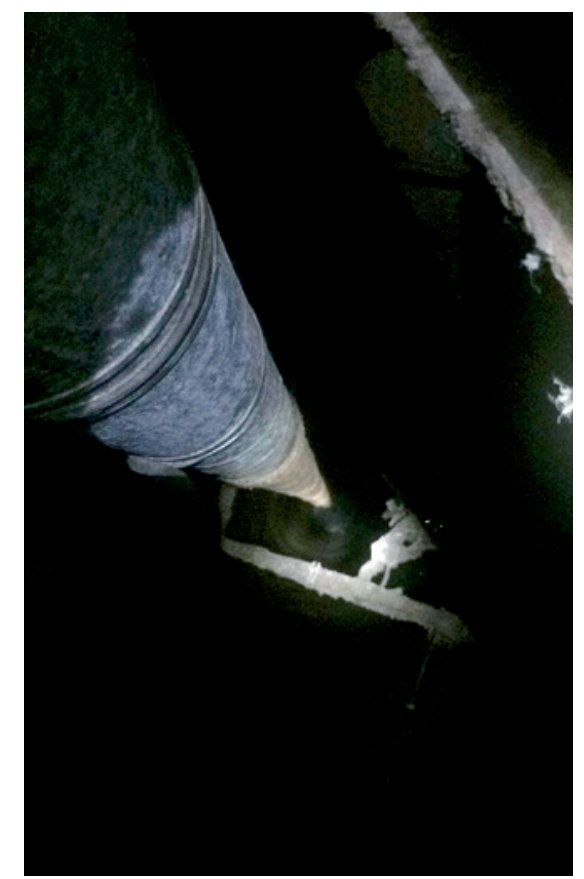

en el caso de las aguas. Por lo cual, la tarea autoencomendada en esta residencia, fue abrir una primera ventana sobre las aguas en su relación pasada, actual y futura con la ciudad, desde un punto de vista cartográfico, pero también social y emocional, contando fundamentalmente con los hallazgos que se puedan encontrar en la ciudad en tiempo presente, a través de un trabajo de campo, autoetnográfico ${ }^{[7]}$, tal y como si fuera un caso forense, donde hay que desentramar un crimen cometido a la ciudad. ${ }^{[8]}$

\section{RECORRER EL TERRITORIO A PIE AL ENCUENTRO CON LAS RUINAS DEL AGUA}

La propuesta comienza con el desprenderse de las cartografías, las rutas y paisajes conocidos para sumergirse en el territorio de lo desconocido, introducirse en estos lugares ignorados, inexistentes para la ciudad, pues no son parte de sus registros cartográficos. Destapar el Santiago oficial para explorar el suboficial, de manera libre y azarosa, atravesando los nuevos escenarios que allí existen para descubrir cuáles son los paisajes de la ruina, de las creaciones pasadas.

Este proyecto nace desde la profunda necesidad de volver a mirar el territorio, de volver a explorarlo, de volver a recorrerlo, de volver a perderse en él (Kuncar, 2010, p. 20).

En la misión autoencargada de explorar a pie el territorio, perdiéndose en este para ir en la búsqueda de las infraestructuras todavía

[7] Se usará la autoetnografía, una técnica de investigación cualitativa, donde tendrán cabida lo subjetivo, las emociones y las narraciones personales.

[8] El arquitecto Eyel Weizman ha acuñado el término "Arquitectura Forense" (Forensic Architecture). Para dar paso una metodología de práctica forense en la investigación de diversos casos urbanos que requieren ser desentrañados para encontrar una solución basada, en la mayoría de los casos, en la justicia y/o en los organismos de paz mundiales. Véase http://www.forensic-architecture.org/

existentes del agua, se realizan exploraciones por los subterráneos de diferentes edificios del centro de Santiago, encontrándose diversos vestigios, en forma de pozos profundos, norias y demás instalaciones relacionadas a la captación, almacenaje y distribución de las aguas de la zona centro de la ciudad. Se han recorrido los edificios: Galería Alessandri, Edificio Plaza de Armas, Paseo Phillips, Pasaje Edwards, Galería Astor, Edificio Gran Palace, Edificio del Banco del Estado. A continuación se detallan estas exploraciones y los hallazgos percibidos.

En la primera visita, realizada a la Galería Alessandri, Calle Huérfanos con Bandera, se descubre el primer pozo. Allí, en el subterráneo -2 se localiza, tras una puerta cerrada con un candado y un cartel que indica "pozo profundo".

Se encuentra en una pequeña habitación, es de un diámetro de no más de 80 centímetros. En su interior, justo en la mitad de la circunferencia, baja un grueso tubo de acero hasta llegar al agua. En los apuntes del trabajo de campo de la autora se relata: 
Trato de mirar a ver si alcanzo a ver el agua, pero la oscuridad y la profundidad del pozo (unos 100 metros) me dificultan la misión. Apoyo mi cabeza en la tapa de seguridad que cubre el hueco que deja el pozo, e intento buscar con la mirada por cada orificio por el que se pueda ver algo. El sonido del torrente es claro y se dramatiza con el eco de la profundidad. Finalmente, y luego de varios intentos, logro enfocar la vista en el agua. Allá lejos observo el torrente en acelerado movimiento. Para mi sorpresa, me indican que el pozo está activo desde el año de su construcción en 1900, diez años antes de la construcción del edificio, y que lo alimenta de agua desde entonces. ¿2Qué habrá habido antes de este edificio que se alimentaba de este pozo? Me pregunto (Observaciones de campo, Kuncar, 2014).

El funcionamiento del pozo consiste en la extracción de aguas profundas a través de una bomba extractora que impulsa el agua hasta un estanque que se encuentra en el mismo subterráneo pero a un nivel más alto, esas aguas deben estar siempre en movimiento con un sistema de nivelación y limpieza, posteriormente suben por tuberías interiores hasta una piscina que se encuentra en el nivel más alto, en la terraza, y desde ahí arriba desciende repartiendo agua a todos los departamentos (FIGURA 7).

En los apuntes del trabajo de campo de la autora durante la exploración al Edificio Plaza de Armas en calle 21 de Mayo, se relata:

El técnico del edificio nos confirma la existencia de una noria activa en el subterráneo, aunque no utilizada por el edificio. Nos indica que no hay registros del momento en que se dejó de usar, y que, con el pasar de los años, el deterioro se ha hecho presente, se han arrojado escombros propios del edificio a este vacío que se cree tenga aproximadamente unos $120 \mathrm{~m}$ de profundidad.

Para llegar hasta allí, bajamos un primer subterráneo, pasando por los cines porno

7. Esquema sistema de extracción de aguas desde las aguas profundas hacia el edificio. Galería Alessandri. Apuntes de campo de la autora.

(

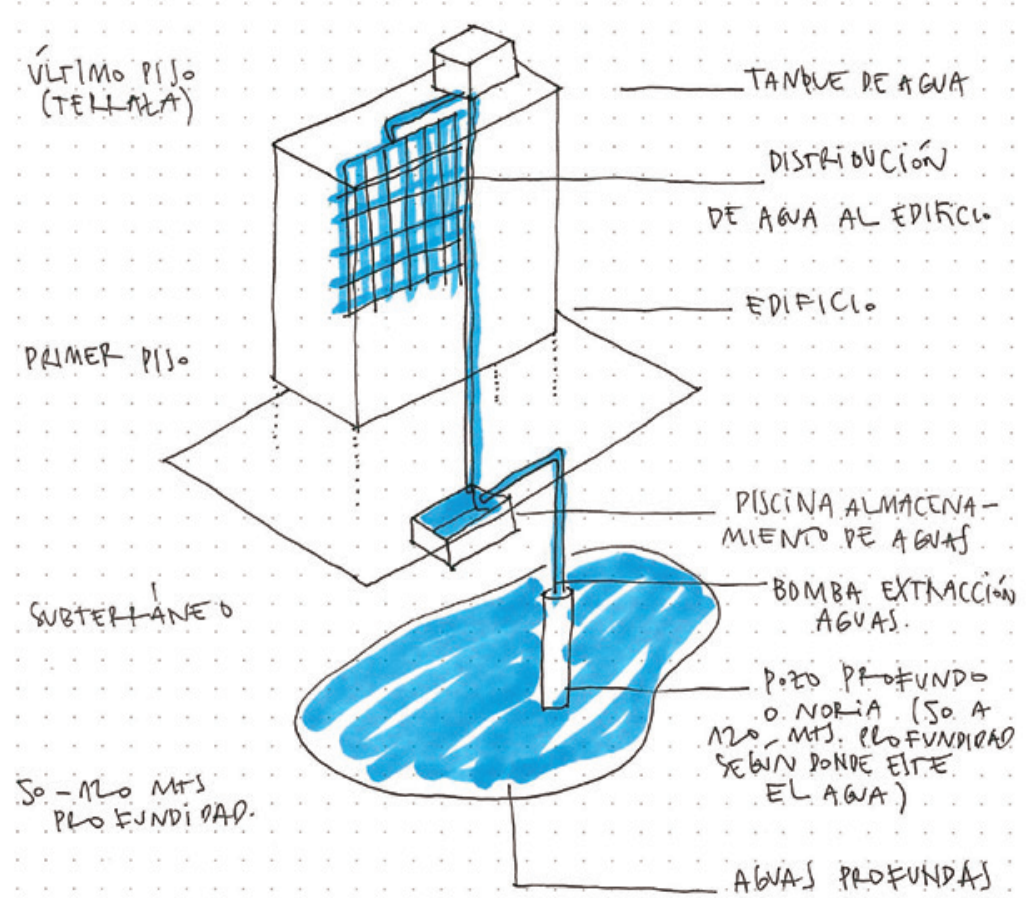

Nilo y Mayo, para seguir bajando a un segundo subterráneo. Unas delgadas escaleras nos llevan a un esbelto pasillo, lúgubre y excesivamente húmedo, iluminado por pocos tubos fluorescentes que tintinean. El largo pasillo desemboca en una sala oscura donde se encuentra el pozo, las dimensiones que tiene son sorprendentes, al menos un diámetro de $1,60 \mathrm{~m}$. Su forma y materialidad nos remontan a un período histórico muy anterior. Al asomarse lo primero que se ve es una antigua escalera metálica, por el estado en el que se encuentra imaginamos sea de la misma época en que se construyó la noria, se desarma con solo tocarla y los pedazos de fierro caen hasta topar con escombros que impiden ver el fondo del pozo. Hacemos algunas pruebas de profundidad tirando los hierros de la escalera y tomamos el tiempo para ver cuánto demoran en llegar hasta el final.

No se logra ver el agua, porque los escombros nos tapan la vista. El técnico introduce una pequeña ampolleta amarrada a un cable de 30 metros. Comienza a bajar la ampolleta encendida por la noria. La luz va alumbrando de a poco las paredes húmedas del pozo. Con destreza el técnico va bajando para no quebrar la ampolleta y logra superar los escombros, los que hacen de filtro a la luz. Cuando ya está por terminarse el cable del foco de luz, logramos ver como el agua salpica las paredes de la noria y finalmente, al fondo del todo, vemos el debilitado torrente de agua que corre con fluidez (Kuncar, 2014). 
8. Noria del Edificio Plaza de Armas. Momento en el que se realizan las tomas audiovisuales. Fotografía de la autora, diciembre 2014.
9. Interior del pozo del Edificio Plaza de Armas iluminado con una ampolleta. Toma audiovisual. Fotografía de Claudia Aravena Abugosh, diciembre 2014
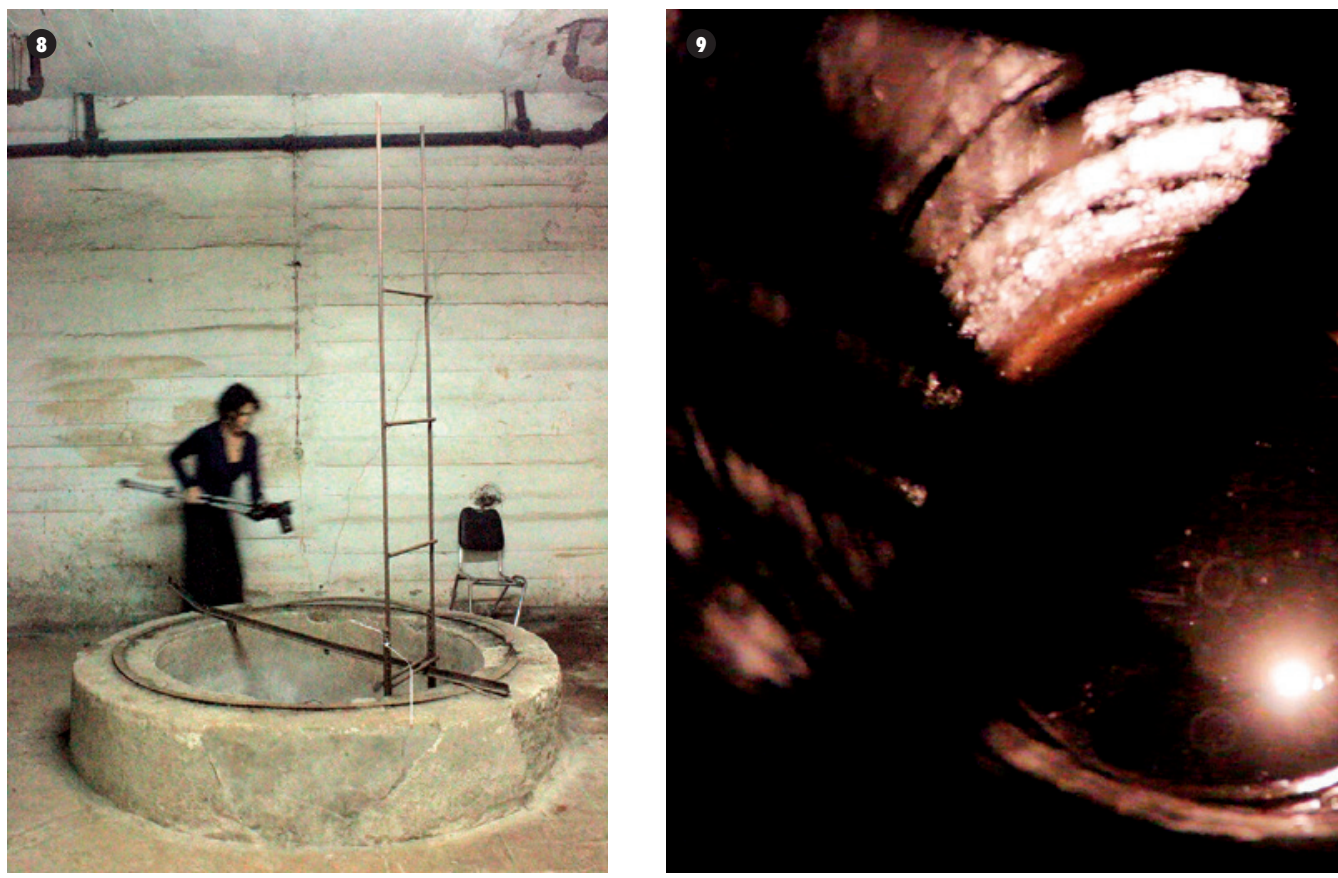

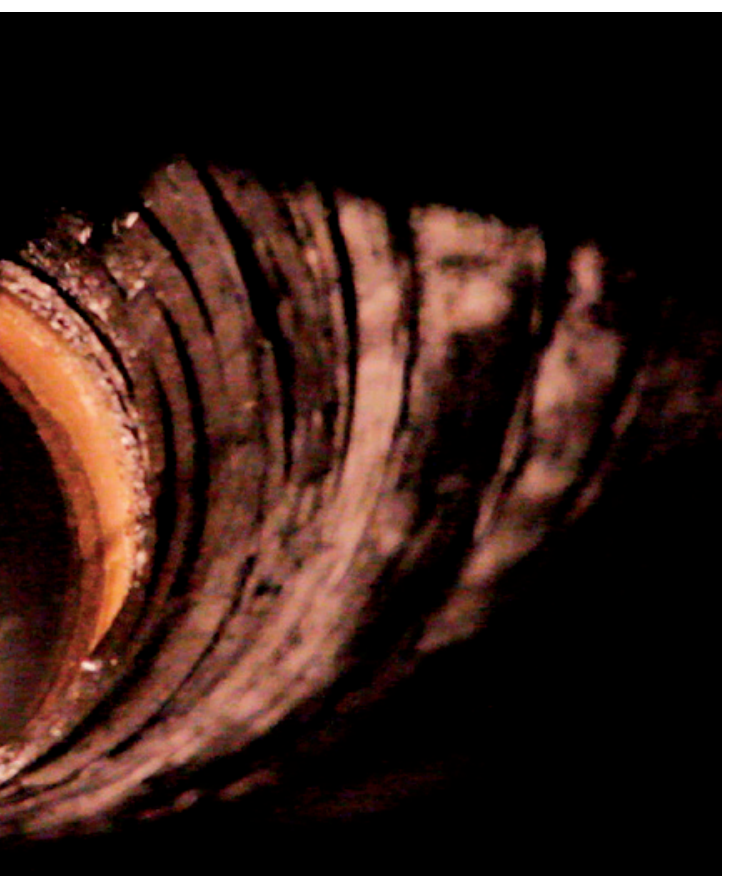

Se visita también el edificio del Banco del Estado, en calle Morandé con Alameda. Allí, en el subterráneo -3 se encuentran las maquinarias de extracción de agua que dieron vida a los dos pozos subterráneos que posee el edificio, uno por calle Morandé y otro por Bandera. En conjunto, llegaron a llenar dos estanques de 57 mil litros de agua pura, que salía desde la tierra. Actualmente ambos pozos se encuentran secos.

El sistema de extracción y gestión del agua subterránea se hacía de manera similar a los demás casos visitados. Actualmente en el edificio se utilizan las mismas tuberías de cobre de la época para llevar el agua potable de la red convencional. Llama la atención el perfecto estado de las instalaciones y la limpieza y grandeza del lugar donde se ubican. Habitan allí enormes tuberías de cobre pintadas cada una de un color correspondiente según normativa, junto a potentes calderas de acero utilizadas con el mismo sistema original de quema de carbón para calentar las aguas. Los pozos profundos se conservan también intactos. De las paredes cuelgan algunos planos de los circuitos de agua originales del edificio y también carteles que indican la presencia del pozo. Todo remite a una zona de exposición de las antiguas instalaciones y sistema de extracción de aguas que tuvo el edificio en sus orígenes.

Se visitaron también los pozos profundos del Paseo Phillips, de Pasaje Edwards, de la Galería Astor, del edificio Gran Palace. Todos ellos se encontraban tapados.

Las metodologías utilizadas permitieron descubrir y recorrer empíricamente algunos de los elementos que hablan de la compleja relación sociedad-agua del casco histórico de Santiago. A través de la metodología empleada se ha podido conocer el estado en el que se encuentran y dejar registros visuales y escritos de cada uno de estos vestigios. Los registros han sido gráficos, a través de fotografías, vídeos y audios, y también técnicos a través del conocimiento de las dimensiones y profundidad de cada pozo o noria, la época de construcción aproximada, al año de cierre en el caso de aquellos que se encuentran tapados, el funcionamiento y uso actual, el caudal aproximado, entre otros.
La investigación de campo ha sido complementada con una revisión y relectura de cartografías e investigaciones, las que han permitido situar estos hallazgos en un lugar de la geografía y en un momento de la historia de Santiago.

Esta ha sido la primera aproximación experiencial al territorio de las aguas en el casco histórico de la ciudad, sin embargo, aún queda mucho por investigar, explorar, descubrir y proponer.

\section{MUESTRA PAISAJE CIEGO, CANCHA SANTIAGO}

Para exponer el avance y los resultados de la investigación se han propuesto tres instancias de exposición. La primera, una muestra "work in progress" del trabajo realizado, donde el objetivo era contar con la opinión del público visitante. La segunda instancia comprendía un conversatorio junto a los investigadores José Rosas Vera, Germán Hidalgo Hermosilla y Wren Strabucchi Chambers; la tercera instancia fue 
10. Pozo profundo y sistema de extracción de aguas del Edificio del Banco del Estado. Fotografía de la autora, enero 2015.

11. Cartel indicativo de la presencia de un pozo profundo en el edificio del Banco del Estado. Fotografía de la autora, enero 2015.

12. Pozo subterráneo del Paseo Phillips. Actualmente se encuentra en una plaza de estacionamientos del edificio, tapado. Fotografía de la autora, diciembre 2014.
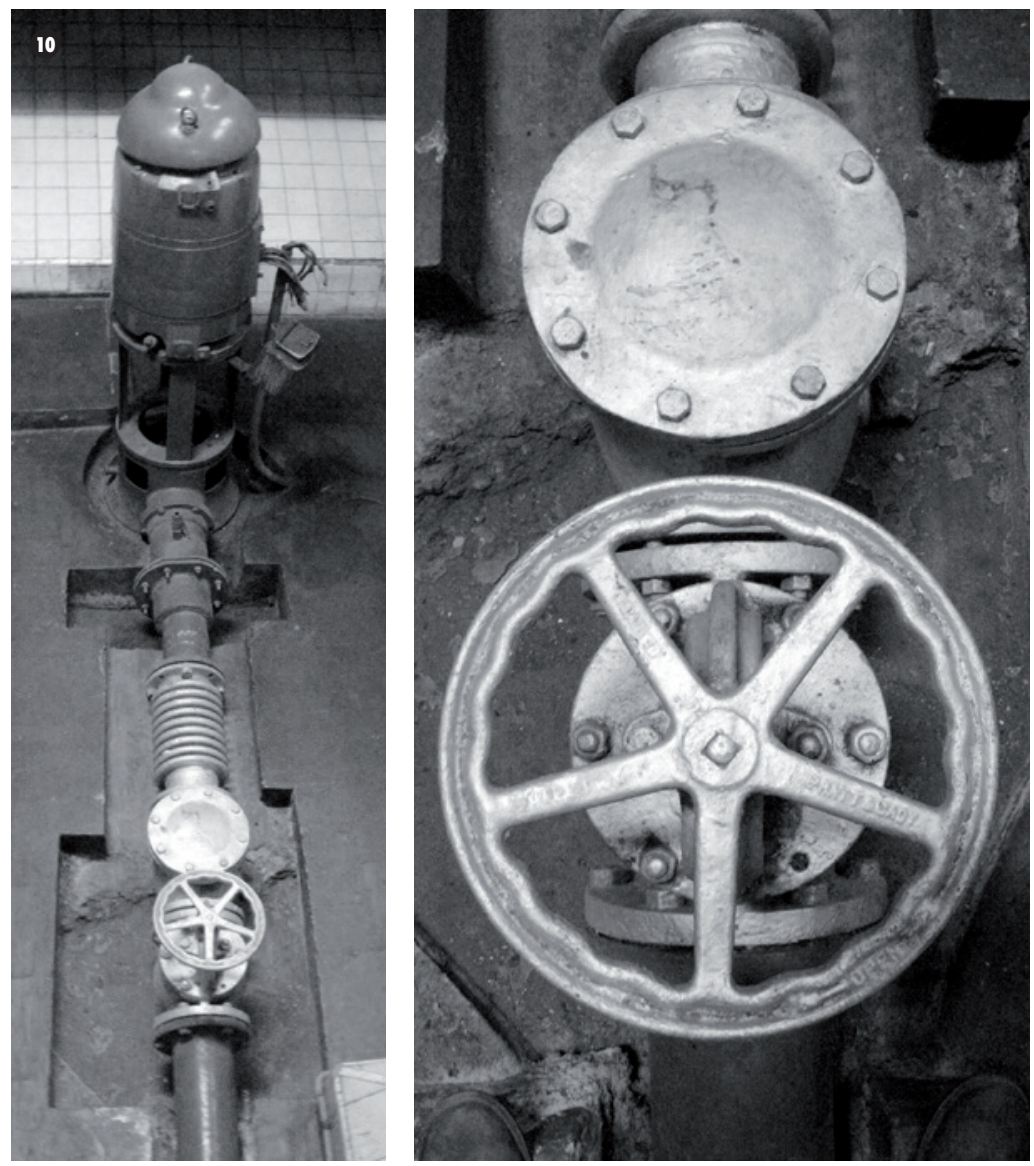

la muestra final, donde se entremezclaron ambos trabajos: aguas y no videntes.

La exposición final de la residencia comprendía un mapa del casco histórico de Santiago, donde se superpusieron la red de acequias de 1890 reflejadas en el plano de Bertrand y los desplazamientos de los no videntes en la ciudad, una capa de cultura y una capa de civilización, ambas habitando conjuntamente y de manera invisible en la ciudad. En la sala principal se contaba con una instalación audiovisual, dos proyecciones de gran formato que narraban de manera entremezclada el hallazgo de pozos subterráneos y norias, con los movimientos y acciones cotidianas de los no-videntes. En la mitad de la sala, se construyó una noria de dimensiones reales con bloques de ladrillo, dentro de la cual se proyectaban imágenes de un no vidente realizando una acción cotidiana: ordenando por tamaño y forma diferentes dinosaurios de plástico para venderlos.

La muestra puso de manifiesto la complejidad y diversidad de tramas que habitan en el casco histórico de la ciudad. A la vez que permitió visibilizar la existencia de ruinas asociadas al agua y mostrar el estado en el que se encuentran.
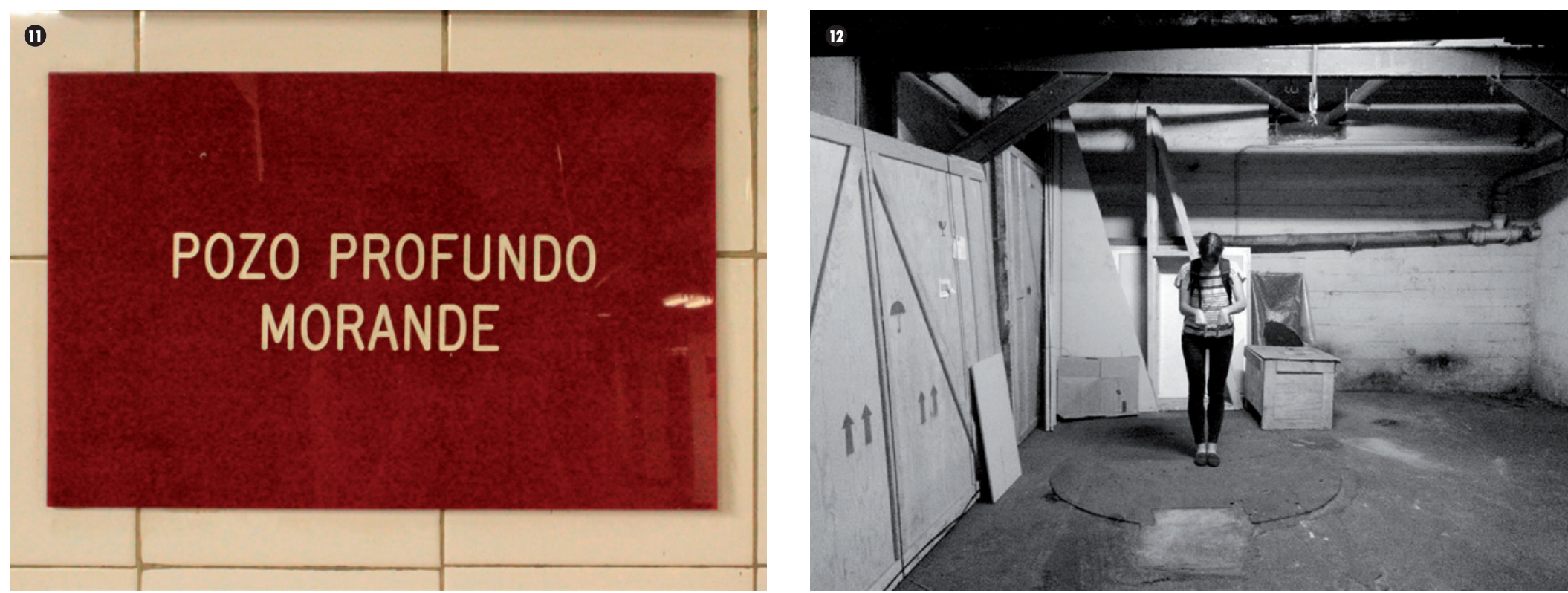


\section{CONCLUSIONES}

En la experiencia de indagar la ciudad a través de exploraciones urbanas, en la búsqueda por reconstituir la manera en que el agua fue relacionándose históricamente con la ciudad, han sido fundamentales los hallazgos para entender que más allá de las revisiones bibliográficas, históricas y cartográficas que se puedan hacer, el recurso hídrico sigue latente, y por ende vulnerable a los cambios que ocurran en la ciudad.

La residencia fue reveladora en el hecho de que el casco histórico que conocemos fue construido, en muchas de sus partes, sobre caudalosos cursos de agua, y, de este modo, los vestigios encontrados se convierten en pistas claves de esta historia sepultada, silenciada, imbunchada ${ }^{[9]}$. Esto abre la investigación a un sinfín de preguntas que aún quedan por resolver, e incita a seguir profundizando en los hallazgos encontrados e ir en la búsqueda de más vestigios.

El agua fue enterrada y sobre ella fueron construidas las sucesivas ciudades de Santiago. Esta investigación busca ser un inicio, una provocación, una primera exploración in situ de los rastros que puedan ayudar a reconstruir el tejido original y posteriormente a rememorarlo.

Darles visibilidad a los cursos de agua históricos de la ciudad de Santiago, supone darles un valor como patrimonio, en tanto a las obras asociadas a la captación, almacenamiento y distribución, manejo y uso, como a su influencia en la conformación del territorio de la ciudad. Esto permitiría construir un relato histórico y espacial entre el agua y la sociedad a través de sus vestigios. Conocer estos lugares y objetos del patrimonio del agua da acceso a lecciones que

13. Muestra "work in progress". Todo el material recolectado hasta ese momento se puso a disposición en la sala de Cancha en formato de mapas, escritos, fotografías y reconstrucciones. Fotografía de la autora, diciembre 2014.

14 y 15. Exposición final: cartografía en tres dimensiones, tejida con hilos de colores para señalar por una parte, los desplazamientos cotidianos de los no-videntes en el centro y por otra, la red de acequias de la ciudad de 1980. Fotografía de Cancha, abril 2015.

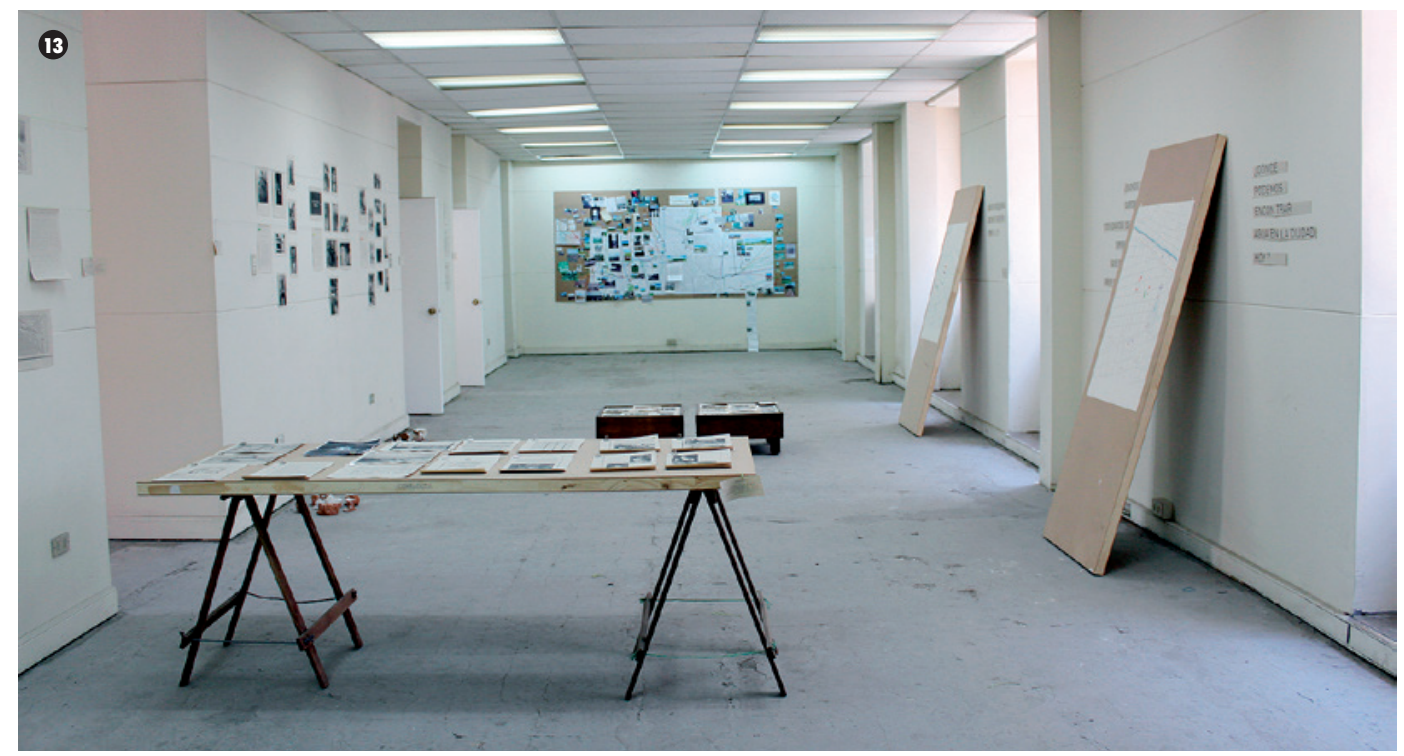

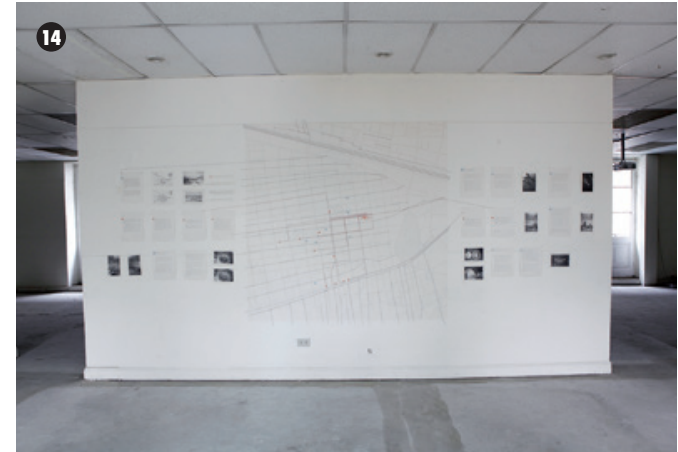

han sido legadas por generaciones pasadas. Saber estas lecciones hace reflexionar en torno a la historia social y cultural que acompañan, siendo parte fundamental del desarrollo material de la ciudad y el entendimiento del rol que ha tenido el agua en la organización de Santiago.

Considerando que, en algunos puntos de la ciudad histórica, el agua sigue fluyendo,

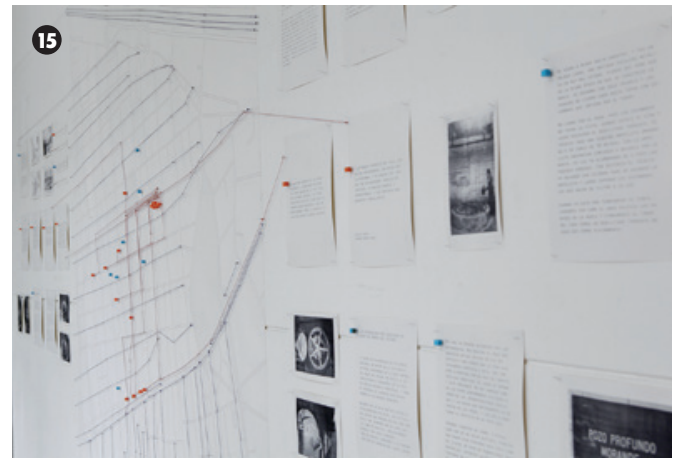

la manera de volver a traer estos cursos a la superficie podría ser a través de microintervenciones urbanas que permitiesen un levantamiento del pavimento y la liberación del fluido. Con esto, la reactivación de zonas del área central para ser transformadas en áreas públicas con una relevancia tanto histórica como actual para la ciudad. ${ }^{[10]}$

[9] Imbunche: Término utilizado por Carlos Franz (La Muralla Enterrada, Franz, 2004), para referirse a la ciudad como un cuerpo desmembrado, mutilado, que oculta y no reconoce o se avergüenza de sus barrios, su memoria y su identidad.

[10] En la ciudad de Bolonia, en Italia, se ha realizado la apertura de un canal que estaba cubierto. El canal Navile como se denomina, fue donde originalmente se encontraba el viejo puerto de Bolonia. Esta intervención ha dado paso a la construcción del Museo de Arte Contemporánea (MAMBO) y una serie de estructuras que han activado ese espacio, convirtiéndolo en una riqueza para la ciudad a partir del descubrimiento de sus aguas. Véase http://www.comune.bologna.it/media/files/progettonavilegennaioa.pdf 
16, 17, 18 y 19. Exposición final: muestra audiovisual. Fotografía de Cancha, abril 2015.
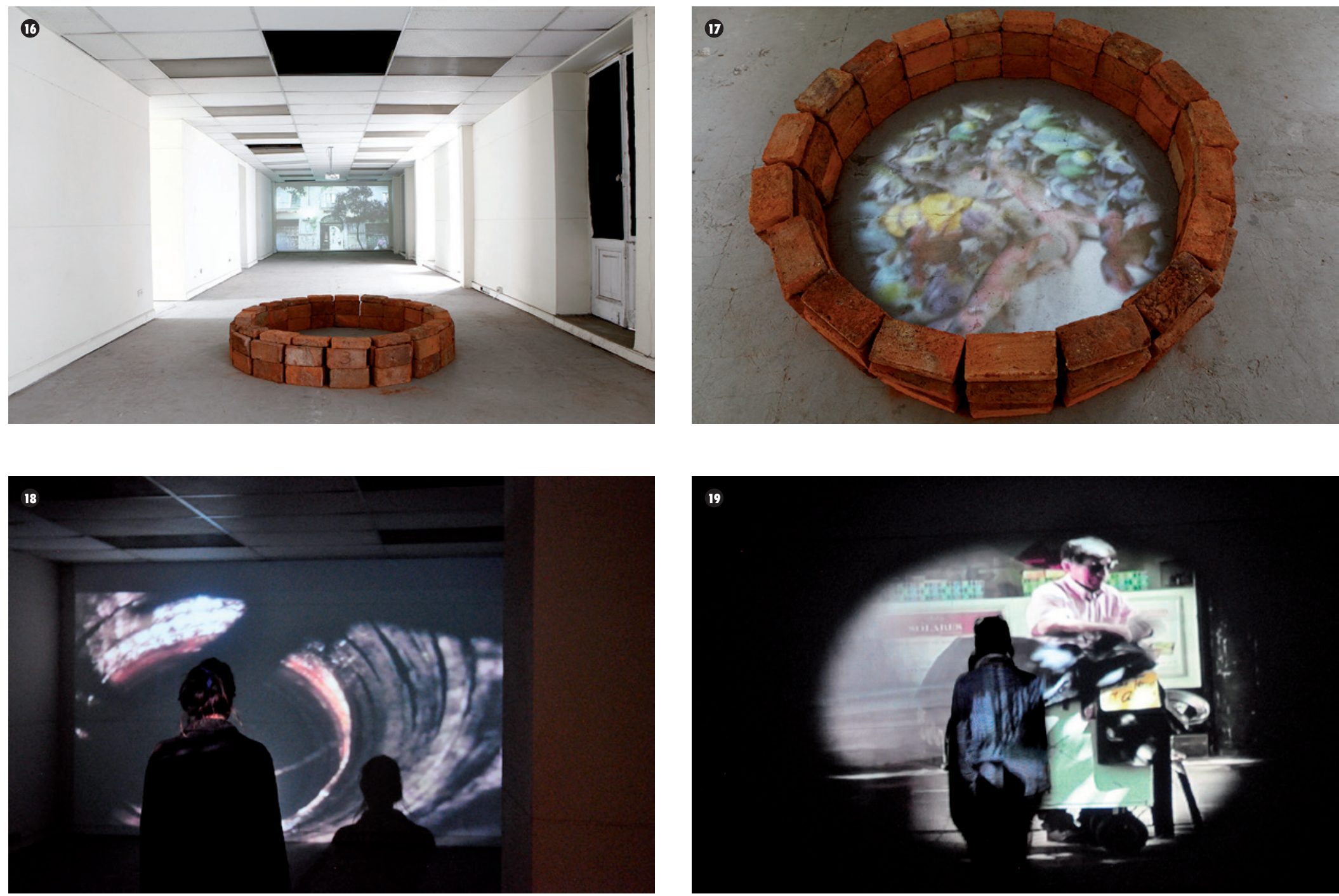

\section{REFERENCIAS BIBLIOGRÁFICAS}

Auge, M. (2003). El tiempo en ruinas. Barcelona: Gedisa Editorial.

Back, L. (2007). The art of listening. Londres: Bloomsbury.

Cacciari, M (2010). La ciudad. Barcelona: Gustavo Gili.

Careri, F. (2002). Walkscapes, el andar como práctica estética. Barcelona: Gustavo Gili.
Feliu, G. (1969). Tomás Thayer Ojeda (1877-1960). Las investigaciones históricas y la bibliografía colonial. Santiago: Bibliógrafos chilenos.

Franz, C. (2004). La muralla enterrada. Santiago: Planeta.

Kuncar, C. (201 1). Pidgin Santiago, Mercado Latinoamericano Abierto. (Memoria de título de arquitecto inédita). Universidad de Chile, Santiago de Chile.
Piwonka, G. (1999). Las aguas de Santiago de Chile, 1541-1999. Santiago: Editorial Universitaria. Rosas, J.; Hidalgo, G. \& Strabucchi, W. (2013). El callejero de Bertrand, Lecciones del plano detallado de Santiago de 1890. Revista 180, (32).

Weizman, E., (2007). Caminar atravesando muros. Eipcp. Transversal texts. 